OPEN ACCESS

Edited by:

Naoki Osada,

Hokkaido University, Japan

Reviewed by:

Marcial Escudero,

University of Seville, Spain

Kiwako S. Araki,

Ritsumeikan University, Japan

*Correspondence:

Zhenyuan Sun

Ikyszy@126.com

${ }^{\dagger}$ These authors have contributed equally to this work.

Specialty section:

This article was submitted to Evolutionary and Population Genetics,

a section of the journal

Frontiers in Plant Science

Received: 24 November 2015 Accepted: 04 March 2016 Published: 18 March 2016

Citation:

Zhai F, Mao J, Liu J, Peng X, Han L and Sun Z (2016) Male and Female

Subpopulations of Salix viminalis Present High Genetic Diversity and

High Long-Term Migration Rates between Them.

Front. Plant Sci. 7:330. doi: 10.3389/fpls.2016.00330

\section{Male and Female Subpopulations of Salix viminalis Present High Genetic Diversity and High Long-Term Migration Rates between Them}

\author{
Feifei Zhai ${ }^{1,2+}$, Jinmei Mao ${ }^{1,2,3 \dagger}$, Junxiang Liu ${ }^{1,2}$, Xiangyong Peng ${ }^{1,2}$, Lei Han ${ }^{1,2}$ and \\ Zhenyuan Sun ${ }^{1,2 *}$
}

1 State Key Laboratory of Tree Genetic and Breeding; Research Institute of Forestry, Chinese Academy of Forestry, Beijing, China, ${ }^{2}$ Key Laboratory of Tree Breeding and Cultivation, State Forestry Administration, Beijing, China, ${ }^{3}$ Research Institute of Economic Forest, Xinjiang Academy of Forestry, Xinjiang, China

Dioecy distributed in 157 flowering plant families and 959 flowering plant genera. Morphological and physiological differences between male and female plants have been studied extensively, but studies of sex-specific genetic diversity are relatively scarce in dioecious plants. In this study, 20 SSR loci were employed to examine the genetic variance of male subpopulations and female subpopulations in Salix viminalis. The results showed that all of the markers were polymorphic $\left(\mathrm{N}_{\mathrm{a}}=14.15, \mathrm{H}_{\mathrm{e}}=0.7566\right)$ and workable to reveal the genetic diversity of $S$. viminalis. No statistically significant difference was detected between male and female subpopulations, but the average genetic diversity of male subpopulations $\left(\mathrm{N}_{\mathrm{a}}=7.12, \mathrm{H}_{\mathrm{e}}=0.7071\right)$ and female subpopulations $\left(\mathrm{N}_{\mathrm{a}}=7.31, \mathrm{H}_{\mathrm{e}}=0.7226\right)$ were high. Under unfavorable environments (West Liao basin), the genetic diversity between male and female subpopulations was still not significantly different, but the genetic diversity of sexual subpopulations were lower. The differentiation of the ten subpopulations in $S$. viminalis was moderate $\left(F_{S T}=0.0858\right)$, which was conformed by AMOVA that most of genetic variance (94\%) existed within subpopulations. Pairwise $F_{S T}$ indicated no differentiation between sexual subpopulations, which was accompanied by high long-term migrate between them $(M=0.73 \sim 1.26)$. However, little recent migration was found between sexual subpopulations. Therefore, artificial crossing or/and transplantation by cutting propagation should be carried out so as to increase the migration during the process of ex situ conservation.

Keywords: dioecy, Salix viminalis, genetic diversity, genetic differentiation, migration rate

\section{INTRODUCTION}

Dioecious plants are not only an important part of terrestrial ecosystems, but also occupy a dominant position in forest ecosystem (Zhai and Sun, 2015). Among about 240,000 angiosperm species, 14,620 species (about 6\%) are dioecy which is distributed in 157 flowering plant families and 959 flowering plant genera (Renner and Ricklefs, 1995). Morphological and physiological differences between males and females have been studied in many species, which find that the 
differences are more remarkable in adversity (Dawson and Ehleringer, 1993; Li et al., 2007; Zhao et al., 2011). Males and females may exhibit sexual differences because of different resource demands and allocation (Li et al., 2013). Usually, females invest more resource to reproduction, while males invest more resource in chemical or/and structural defenses (Cornelissen and Stiling, 2005). Males are often more adaptive than females in environmental stress (Dudley and Galen, 2007; Buckley and Avila-Sakar, 2013; Han et al., 2013), while some females can also be more tolerant to adversity than males (Dawson and Bliss, 1989; Montesinos et al., 2012). However, sexual differences are mainly focused on the physiological adaptation of males and females, few studies explore the genetic diversity of sexual populations at molecular genetics.

Usually, population genetic diversity can affect the adaptation and tolerance of a species, especially the genetic diversity of sexual populations (Reed and Frankham, 2003; Johansson et al., 2007; Ilves et al., 2013). Furthermore, due to that the metabolic efficiency or/and disease resistance might be increased to better afford reproduction cost, sexual genetic variation could play an important role in reproductive success (Ashman and Diefenderfer, 2001; Charpentier et al., 2005). Besides, information about the genetic diversity of males and females will increase the chances to get new genetic combination (Heikkrujam et al., 2015). Thus, assessment the genetic diversity of male and female populations is conducive to know the adaptation and evolutionary potential of a species and contributes to breed new varieties.

Salix viminalis is a dioecious pioneer shrub belongs to the genus Salix, Salicaceae. The males and females bear distinct catkins and have separate flowers which can be insects- or windpollinated (Karp et al., 2011). S. viminalis is widely distributed across the world, ranging from Atlantic Ocean eastward to Siberia and from Sweden southward to the Mediterranean Sea (Lascoux et al., 1996). In recent years, S. viminalis has been bred for bioenergy production owing to high biomass within short period, fast initial growth, perennial habit, repeated regrowth from coppiced stools and favorable environmental credentials (Berlin et al., 2014). Moreover, S. viminalis is well suited to phytoremediation of heavy mental (Klang-Westin and Perttu, 2002; Hermle et al., 2007) and organic contaminated (Ucisik and Trapp, 2006) soils. However, S. viminalis has not been exploited in China.

Przyborowski and Sulima (2010) have employed RAPD markers to analyze the genetic diversity and genetic similarity among 19 genotypes of $S$. viminalis, the study has identified suitable input materials for creative breeding. By using 16 isozyme loci to study the population structure of $S$. viminalis collected in Poland, Germany and Austria, it is found that the overall population differentiation is low (Lascoux et al., 1996). SSR analysis also reveals low differentiation of $S$. viminalis populations in Czech Republic, and majority of genetic variation exist within population (Trybush et al., 2012). However, as a dioecious plant, whether the genetic diversity of $S$. viminalis is related to sex has not been studied.

China, as a distribution center of willows, is rich of $S$. viminalis resources, especially in Da Hinggan Mountains. To explore the genetic diversity of males and females of $S$. viminalis, five populations (each population contains a male subpopulation and a female subpopulation) were collected in Da Hinggan Mountains, and 20 SSR markers were used to assess the genetic diversity, genetic structure and gene flow of male subpopulations and female subpopulations in $S$. viminalis.

\section{MATERIALS AND METHODS}

\section{Sample Collection and DNA Extraction}

$S$. viminalis, a diploid $(2 n=2 x=38)$, outcrossing perennial species, which is predominantly found along streams and rivers and in other wet places. During blossom season in late April and early May in 2015, cuttings of 144 adult individuals of $S$. viminalis were collected from five populations across Ergun and West Liao basin, i.e., GH, TL, KDE, ZD, and DHQ (Figure 1, Table 1). The five populations cover an area of $3-16 \mathrm{~km}^{2}$ and have very high density of 60-70 no./are. Habit along Zhadun river has been effected by human activities, the distribution of S. viminalis are separated by road or farmland. We selected continuous distribution willow in this region as $\mathrm{ZD}$ population. DHQ and TL populations comprise S. viminalis as dominant species and Salix linearistipularis as associated species. The other three populations are comprised of $S$. viminalis as dominant species, Salix schwerinii and $S$. viminalis var. angustifolia as associated species. In every population, 13 15 male-female pairs of $S$. viminalis were randomly sampled by paired sampling method. The distance between male and female plant of each pair was controlled within $2 \mathrm{~m}$, while the distances between pairs were at least $50 \mathrm{~m}$ apart. The males and females within a population are defined as male subpopulation and female subpopulation respectively. Each population contains a male subpopulation and a female subpopulation. After the cuttings were transported to greenhouse, they were propagated at once. One month later, fresh leaves were picked and stored at $-80^{\circ} \mathrm{C}$ for molecular analyses. Total DNA was extracted from $150 \mathrm{mg}$ fresh leaves following the modified cetyltrimethyl ammonium bromide (CTAB) protocol described by Doyle (1987). The DNA concentration was checked with a spectrophotometer (NAS-99, ACTGene Company) and the quality of DNA was verified on a $1.2 \%$ agarose gel electrophoresis.

\section{SSR Analysis}

A total of 20 SSR makers were selected from published literatures (Barker et al., 2003; Stamati et al., 2003; Kikuchi et al., 2005; Trybush et al., 2012) which were shown in Supplementary Table 1 . The PCRs was performed in a volume of $15 \mu \mathrm{l}$ containing $6.0 \mu \mathrm{l} 2.5 \times$ PCR buffer (KAPA Taq HotStart PCR Kits, KAPA Company), $1.0 \mu$ l of each of the forward and reverse primers $(5 \mu \mathrm{M}), 1.0 \mu \mathrm{l}$ of template DNA, $0.5 \mathrm{U}$ of Taq DNA polymerase, and water to $15 \mu$ l. The amplifications were carried out by the following process: an initial step of $10 \mathrm{~min}$ at $95^{\circ} \mathrm{C}$, followed by 40 cycles of $30 \mathrm{~s}$ at $95^{\circ} \mathrm{C}, 30 \mathrm{~s}$ at $58^{\circ} \mathrm{C}, 30 \mathrm{~s}$ at $72^{\circ} \mathrm{C}$, and ending with a final extension for $7 \mathrm{~min}$ at $72^{\circ} \mathrm{C}$. The whole cycling was conducted on a GeneAmp 9600 PCR system (Applied Biosystems). To allow multiplexing, the forward primers were fluorescently end-labeled with either 6FAM, VIC, 
NED or PET (Applied Biosystems). After amplification, $1 \mu 1$ of PCR products were added to $0.5 \mu \mathrm{l}$ of ROX-500 size standard (Beijing Microread Gene Technology Co., Ltd) and $8.5 \mu l$ of Hi-Di formamide (Applied Biosystems) in 96 well-plates, and denatured at $95^{\circ} \mathrm{C}$ for $3 \mathrm{~min}$. Then the products were separated by capillary electrophoresis on 3730XL DNA analyzer (Applied Biosystems). Data were scored using the GeneMapper v 4.0 (Applied Biosystems).

\section{Data Analysis}

We applied POPGENE v 1.32 (Yeh et al., 1997) to examine genetic parameters for each locus, including number of observed alleles $\left(\mathrm{N}_{\mathrm{a}}\right)$, number of effective alleles $\left(\mathrm{N}_{\mathrm{e}}\right)$, Shannon's

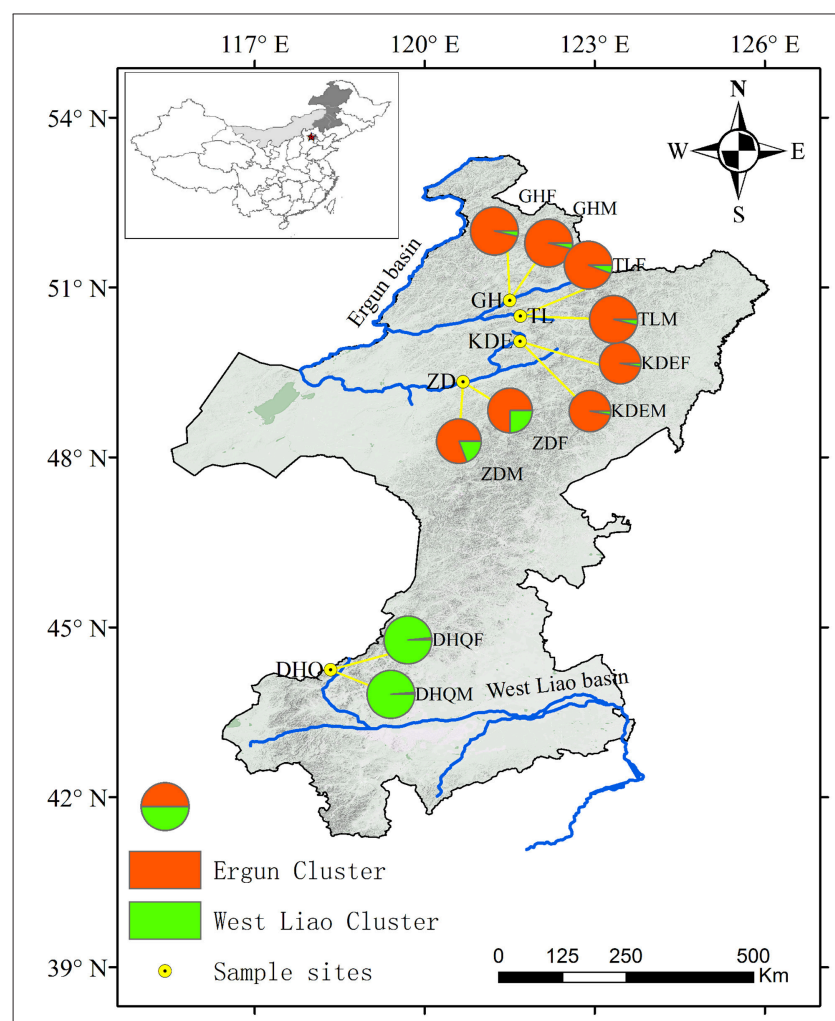

FIGURE 1 | Assignment of S. viminalis individuals from each subpopulation to two clusters ( $K=\mathbf{2}$ identified by STRCUTURE). Pie chart sizes show the sample size of each subpopulation. Pie charts represent probability of each subpopulation belonging to each of the two clusters. Ergun cluster was shown in red color, while West Liao cluster was shown in green color. information index $(\mathrm{I})$, observed heterozygosity $\left(\mathrm{H}_{\mathrm{o}}\right)$, expected heterozygosity $\left(\mathrm{H}_{\mathrm{e}}\right)$, inbreeding coefficient among individuals within subpopulation ( $\left.\mathrm{F}_{\text {IS }}\right)$, inbreeding coefficient of an individual relative to entire population $\left(\mathrm{F}_{\mathrm{IT}}\right)$ and genetic differentiation among populations $\left(\mathrm{F}_{\mathrm{ST}}\right)$. GenAlex v 6.5 (Peakall and Smouse, 2012) was used to calculate the genetic diversity of each subpopulation, containing $\mathrm{N}_{\mathrm{a}}, \mathrm{N}_{\mathrm{e}}, \mathrm{I}, \mathrm{H}_{\mathrm{o}}, \mathrm{H}_{\mathrm{e}}$ and number of private alleles $\left(\mathrm{N}_{\mathrm{p}}\right)$. Besides, statistical tests were performed on SPSS 18.0 (SPSS Inc., Chicago, IL, USA). For each genetic parameter, the differences between male and female subpopulations for both all loci and single locus were analyzed by paired-sample $t$-test with five pairs, while the differences between two basins were analyzed by one-way analysis of variance.

We used Bayesian clustering with an admixture model to analyze the genetic structure of all subpopulations by STRUCTURE v 2.3.4 (Pritchard et al., 2000; Falush et al., 2003). This clustering method applies the Markov Chain Monte Carlo (MCMC) algorithm. Fifteen independent runs were performed for each value of $\mathrm{K}$ ranging from 1 to 10 with a burn-in of 50,000 iterations followed by 100,000 iterations. In addition, the observed genetic variation within and among subpopulations characterized by analysis of molecular variance (AMOVA) was performed on GenAlex. Pair-wise values for genetic differentiation $\left(\mathrm{F}_{\mathrm{ST}}\right)$ were calculated by the AMOVA routine in GenAlex. Permutation procedures (9999 replicates) were used to test the significance of the differentiation between pairs of subpopulations.

Long-term effective population sizes and migration rates were estimated with MIGRATE-N v 3.4 .2 (http://popgen.sc. fsu.edu/Migrate/Migrate-n.html). MIGRATE- N estimates the long- term effective population size $\left(\mathrm{N}_{\mathrm{e}}\right)$ of each subpopulation as parameter $\theta$ (that is $4 \mathrm{~N}_{\mathrm{e}} \mu$, where $\mu$ is mutation rate per site). Long-term migration rates, $M, 4 N_{e}$ generations in the past based on a coalescent approach, were estimated using the maximum-likelihood mode. We adopted Brownian motion model and the Markov Chain was conducted with 10 short chains of 500 and three long chains of 2000, with an increment of 20 . The burn-in at the beginning was 1000. Recent migration rates that occurred in the last few generations were performed on BAYESASS v 1.3 (Wilson and Rannala, 2003) which relies on Markov chain Monte Carlo techniques. The run consisted of $3 \times 10^{6}$ iterations with a sampling frequency of 2000 , and the first $1 \times 10^{6}$ steps were discarded.

TABLE 1 | Sampling locations of S. viminalis populations across Ergun and West Liao basin in China.

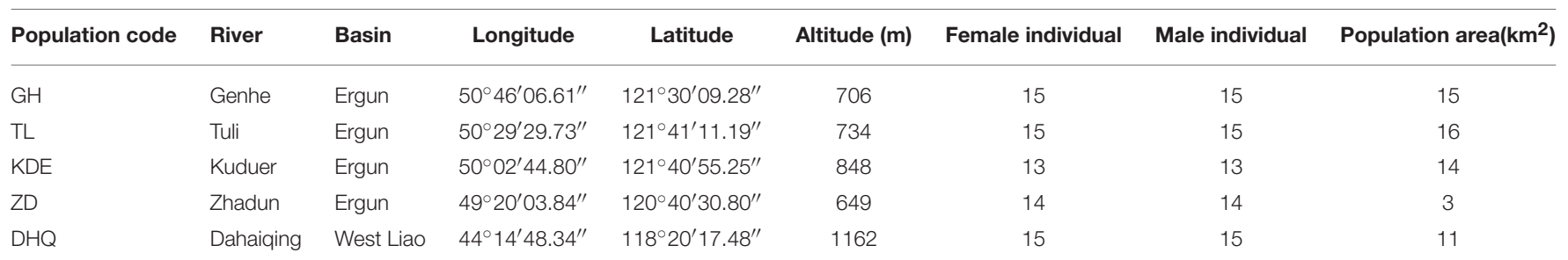




\section{RESULTS}

\section{The Polymorphism of 20 SSR Loci in S. viminalis}

The 20 microsatellite loci used in this study were moderate to high polymorphism and a total of 283 alleles were detected across 144 S. viminalis individuals with an average of 14.15 observed alleles $\left(\mathrm{N}_{\mathrm{a}}\right)$ per locus. The average effective allele $\left(\mathrm{N}_{\mathrm{e}}\right)$ per locus was 5.7645. The Shannon's information index (I) ranged from 0.7084 to 3.1636 with an average of 1.8621. The mean observed heterozygosity $\left(\mathrm{H}_{\mathrm{o}}\right)$ and expected heterozygosity $\left(\mathrm{H}_{\mathrm{e}}\right)$ were 0.6542 and 0.7566 respectively. Higher $\mathrm{H}_{\mathrm{e}}$ values than $\mathrm{H}_{\mathrm{o}}$ at 17 loci except SB430, SB984 and SB1148 indicated heterozygote deficiencies of these loci, which were conformed by $\mathrm{F}_{\mathrm{IT}}$ values (Supplementary Table 1).

\section{Genetic Diversity of Male and Female Subpopulations}

The genetic diversity of 10 subpopulations of $S$. viminalis is shown in Table 2. Although the average genetic diversity and private alleles of female subpopulations $\left(\mathrm{N}_{\mathrm{a}}=7.3100, \mathrm{H}_{\mathrm{e}}=\right.$ $\left.0.7226, \mathrm{~N}_{p}=3.40\right)$ was slightly higher than that of male subpopulations $\left(\mathrm{N}_{\mathrm{a}}=7.1200, \mathrm{H}_{\mathrm{e}}=0.7071, \mathrm{~N}_{\mathrm{p}}=2.20\right.$; Table 2), the difference was not statistically significant by pairedsample $t$-test (Supplementary Table 2). Furthermore, statistical differences of male and female subpopulations at each locus were also analyzed. It was showed that $\mathrm{N}_{\mathrm{a}}, \mathrm{N}_{\mathrm{e}}$, and I of female subpopulations were significantly higher than that of male subpopulations at loci of SB1185 and SB24*, while $\mathrm{H}_{\mathrm{e}}$ of female subpopulations was only significantly higher than male subpopulations at locus of SB24* (Supplementary Table 3). Moreover, that $\mathrm{H}_{0}$ was lower than $\mathrm{H}_{e}$ in nine subpopulations except DHQF indicated heterozygote deficiency for the nine subpopulations, which was accompanied by positive fixation index ( $\mathrm{F}_{\mathrm{IS}}$; Table 2). In addition, the genetic parameters of subpopulations from Ergun basin were significantly higher than that from West Liao basin (Supplementary Table 4).

\section{Genetic Structure and Differentiation of Male and Female Subpopulations}

A clustering carried with STRUCTURE software supported an optimal value of $\mathrm{K}$ to be $K=2$ for both log-likelihood values described by Pritchard et al. (2000) and $\triangle \mathrm{K}$ values following Evanno et al. (2005) (Figure 1, Supplementary Figure 1). One of the clusters (the "West Liao cluster") is represented by individuals from two subpopulations in West Liao basin (DHQF and DHQM). The other cluster (the "Ergun cluster") is represented by individuals from Ergun basin.

The overall genetic differentiation was moderate with a mean F $_{\text {ST }}$ value of 0.0858 (Supplementary Table 1). Analysis of Molecular Variance (AMOVA; Table 3) also revealed that the largest proportion of total variance (94\%) existed within subpopulations and $6 \%$ was attributable to differences among subpopulations. In addition, hierarchical AMOVA was conducted based on two basins (clustering results). For two basins, $11 \%$ of the total genetic variance was ascribed to differences between basins, $1 \%$ was attributed to differences among subpopulations within basins, and the remaining $87 \%$ existed within subpopulations (Table 3). Pairwise $\mathrm{F}_{S T}$ values (Supplementary Table 5) revealed no statistically significant differentiation between male and female subpopulation of the same population. The differentiation was statistically significant between subpopulations from West Liao basin and that from Ergun basin at significant level of 0.001 ( $F_{S T}$ range from 0.099 to 0.162 ). Within Ergun basin, both ZDM and ZDF showed statistically significant differentiation with other subpopulations at level of 0.001 or $0.05\left(\mathrm{~F}_{\mathrm{ST}}\right.$ range from 0.023 to 0.043$)$. However, no statistically significant differentiation was found among subpopulations of GH, KDE, and TL.

\section{Gene Flow between Male and Female Subpopulations}

Long-term effective population size $(\theta)$ values for subpopulations from Ergun basin were bigger ranging from 1.89 (KDEM) to 2.71(TLM), while that for DHQF and DHQM from West Liao basin were smaller which were 0.98 and 0.85 . Long-term migration rates $(\mathrm{M})$ ranged from $0.38\left(\mathrm{M}_{\mathrm{DHQF} \rightarrow \mathrm{GHF}}\right)$ to 1.74 $\left(\mathrm{M}_{\mathrm{TLF} \rightarrow \mathrm{GHM}}\right)$. That the $\mathrm{M}$ values between male and female subpopulations of the same population were $>0.8$ (except $\mathrm{M}_{\mathrm{GHF} \rightarrow \mathrm{GHM}}$ ) indicated high levels of historical gene exchange. There was no significant asymmetrical migration among male and female subpopulations according to overlapping 95\% CIs for estimates of $\mathrm{M}$ in both directions [for example, $\mathrm{M}_{\mathrm{GHF} \rightarrow \mathrm{DHQM}}=$ $0.80,95 \%$ CIs $=(0.68,0.94) ; \mathrm{M}_{\mathrm{DHQM} \rightarrow \mathrm{GHF}}=0.90,95 \%$ CIs $=(0.78,1.03)$; Supplementary Table 6]. Moreover, we also estimated bidirectional gene flow between two clusters (basins) and the results were shown in Figure 2. The gene flow between the two basins was higher (2.24 and 2.08 respectively). However, recent migration among subpopulations estimated by BAYESASS was low and most of it overlapped 0 at the 95\% CIs indicating little or no contemporary migration (Supplementary Table 7).

\section{DISCUSSION}

\section{High Genetic Diversity of Male and Female Subpopulations}

Although the average genetic diversity of female subpopulations $\left(\mathrm{N}_{a}=7.3100, \mathrm{H}_{\mathrm{e}}=0.7226\right)$ and that of male subpopulations $\left(\mathrm{N}_{\mathrm{a}}=7.1200, \mathrm{H}_{\mathrm{e}}=0.7071\right)$ were both high, the genetic diversity of sexual subpopulations was not statistically significant. This was consistent with the study of Myrica rubra that no significant difference was found between males and females (Jia et al., 2015). Male subpopulations possess higher genetic diversity than female subpopulations in Hippophae rhamnoides (Chen et al., 2008) and Pistacia atlantica (Nosrati et al., 2012), but no statistical tests were conducted in these studies. Dioecious plants have evolved mainly to avoid inbreeding (Ainsworth, 2000), the genetic diversity and heterozygosity of dioecious plants, such as Populus euphratica (Wang et al., 2011), Populus tremuloides (Callahan et al., 2013), Myrica rubra (Jia et al., 2015), Juniperus thurifera (Teixeira et al., 2014), and Corylus mandshurica (Zong et al., 2015), are always higher due to obligate outbreeding. However, there are some notable exceptions. For example, Pyrus calleryana presents a high 
TABLE 2 | Genetic diversity of male and female subpopulations in S. viminalis.

\begin{tabular}{|c|c|c|c|c|c|c|c|c|}
\hline Sex & Subpopulation code & $\mathbf{N}_{\mathbf{a}}$ & $\mathrm{N}_{\mathrm{e}}$ & $\mathbf{I}$ & $\mathbf{H}_{\mathbf{o}}$ & $\mathbf{H}_{\mathrm{e}}$ & $F_{\text {IS }}$ & $N_{p}$ \\
\hline \multirow[t]{6}{*}{ Male } & DHQM & 5.3000 & 2.8265 & 1.1308 & 0.5500 & 0.5692 & -0.0009 & 0 \\
\hline & $\mathrm{GHM}$ & 7.7000 & 4.8264 & 1.5957 & 0.6500 & 0.7313 & 0.0672 & 2 \\
\hline & KDEM & 7.0500 & 4.4878 & 1.5578 & 0.7115 & 0.7448 & -0.0015 & 2 \\
\hline & TLM & 8.1500 & 4.9704 & 1.6586 & 0.6333 & 0.7572 & 0.1296 & 7 \\
\hline & ZDM & 7.4000 & 4.1888 & 1.5666 & 0.7000 & 0.7331 & 0.0026 & 0 \\
\hline & Mean & 7.1200 & 4.2600 & 1.5019 & 0.6490 & 0.7071 & 0.0394 & 2.20 \\
\hline \multirow[t]{6}{*}{ Female } & DHQF & 5.3000 & 2.7157 & 1.1555 & 0.5900 & 0.5862 & -0.0560 & 1 \\
\hline & $\mathrm{GHF}$ & 7.8000 & 5.0060 & 1.6426 & 0.6567 & 0.7547 & 0.0829 & 3 \\
\hline & $\mathrm{KDEF}$ & 7.5500 & 5.0398 & 1.6737 & 0.7308 & 0.7792 & 0.0279 & 3 \\
\hline & TLF & 8.7000 & 5.5911 & 1.7486 & 0.6800 & 0.7722 & 0.0786 & 5 \\
\hline & ZDF & 7.2000 & 3.9698 & 1.5220 & 0.6607 & 0.7206 & 0.0561 & 5 \\
\hline & Mean & 7.3100 & 4.4645 & 1.5485 & 0.6636 & 0.7226 & 0.0379 & 3.40 \\
\hline
\end{tabular}

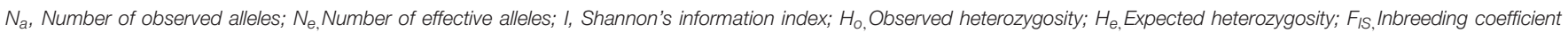
among individuals within subpopulation; $N_{p}$, Number of private alleles.

TABLE 3 | Analysis of molecular variance (AMOVA) of ten subpopulations in S. viminalis by 20 SSR loci.

\begin{tabular}{|c|c|c|c|c|c|}
\hline Source of variation & Degrees of freedom & Sum of squares & Mean squares & Estimated variance & Explained variance (\%) \\
\hline \multicolumn{6}{|l|}{ TEN SUBPOPULATIONS } \\
\hline Among subpopulations & 9 & 188.498 & 20.944 & 0.458 & 6 \\
\hline Within subpopulations & 278 & 1983.033 & 14.311 & 7.156 & 94 \\
\hline \multicolumn{6}{|l|}{ TWO BASINS } \\
\hline Between basins & 1 & 99.243 & 99.243 & 0.926 & 11 \\
\hline Among subpopulations within basins & 8 & 89.255 & 11.157 & 0.118 & 1 \\
\hline Within subpopulations & 278 & 1983.033 & 14.311 & 7.156 & 87 \\
\hline
\end{tabular}

\begin{tabular}{|c|c|c|}
\hline $\begin{array}{c}\text { West Liao Cluster } \\
\theta=2.91 \\
(2.75-3.09)\end{array}$ & $2.24(2.12-2.38)$ & $\begin{array}{c}\text { Ergun Cluster } \\
\theta=3.78 \\
(3.66-3.90)\end{array}$ \\
\cline { 3 - 3 } & $2.08(1.95-2.22)$ \\
\end{tabular}

FIGURE 2 | Graphical representation for results of the migrations estimated using MIGATE-N among two basins. Maximum-likelihood estimates and 95\% confidence intervals (in parentheses) of the long-term migration rate $(\mathrm{M})$ and mutation-scaled effective population size $(\theta)$ are shown.

genetic diversity with $\mathrm{N}_{\mathrm{a}}=9.536$ and $\mathrm{H}_{\mathrm{e}}=0.639$ (Liu et al., 2012).

Genetic diversity is required for populations to adapt environment change, and high genetic diversity contributes to stable evolution and extension of distribution range for a species (Shen and Liu, 2001; Frankham et al., 2002). Although skewed sex ratios presented in populations of $S$. viminalis (with an overall male to female ratio of 1:5), high genetic diversity of male and female subpopulations indicated high stability of populations and this species can also maintain high evolutionary potential over long term. High genetic diversity of subpopulations further explained the extensive distribution of $S$. viminalis. In addition, lower $\mathrm{H}_{\mathrm{o}}$ than $\mathrm{H}_{\mathrm{e}}$ and positive $\mathrm{F}_{\mathrm{IS}}$ values in nine subpopulations indicated a deficiency of heterozygotes for these subpopulations. Such a deficit might be explained by mating among close kin individuals of the opposite sex in S. viminalis (Young et al., 1996; Lowe et al., 2005). In previous studies of Salicaceae family, high positive values of inbreeding coefficients are also observed (Stamati et al., 2007; Lee et al., 2011; Perdereau et al., 2014).

Furthermore, we found that the genetic diversity of subpopulations from Ergun basin was significantly higher than that from West Liao basin. Unfavorable environments may lead to an increase in vegetative reproduction and a decrease in resource-demanding sexuality and thus the genetic variance is lost (Chen et al., 2008). Desiccation in spring and high temperature in summer for Dahaiqing river (West Liao basin) might lead to a lower genetic variability in this study. The males and females of some species behave differently to harsh environments in physiology (Xu et al., 2008; Montesinos et al., 2012), but the unfavorable environment did not lead to differences in genetic diversity between males and females of $S$. viminalis. This might be due to SSR markers are more stable than physiological trains, and current ecological environment caused no selection pressures for male and female subpopulations. The geographic explanation might be that West Liao basin could be regarded as peripheral distribution of $S$. viminalis. Toward the distributional edge, marginal populations are often genetically depauperate caused by chronic genetic drift and low gene flow (Dostálek et al., 2014) and the opportunity to communication 
with other populations would reduce (Wang et al., 2014), so they tend to present lower genetic diversity (Keller et al., 2011; Jiang et al., 2015). The lowest genetic diversity of male and female subpopulation appeared in Zhadun river (ZDF and ZDM), which would be influenced by insect attack, such as Aphrophora intermedia. It has been found that Pinus monticola populations under higher disease pressure possess lower genetic diversity (Kim et al., 2003, 2011). Another reason for the lower genetic diversity might be the interference of human activities.

\section{No Genetic Differentiation, High Long-Term Migration Rates, and Low Recent Migration Rates between Male-Female Subpopulations}

Microsatellite analysis revealed moderate differentiation $\left(\mathrm{F}_{\mathrm{ST}}=0.0858\right)$ of the 10 subpopulations in $\mathrm{S}$. viminalis (Supplementary Table 1). The degree of differentiation was higher than $S$. viminalis populations in Czech Republic $\left(\mathrm{F}_{\mathrm{ST}}=0.050\right.$; Trybush et al., 2012), but was in accordance with our study $\left(\mathrm{F}_{\mathrm{ST}}=0.0761\right)$ in China (unpublished). Moderate differentiation was also conformed by AMOVA that higher level of genetic variance (94\%) was found within subpopulations rather than among subpopulations (6\%). This might be related to the life cycle and breeding system of $S$. viminalis. In general, the differentiation among populations of long-lived woody, wind-pollinated, out-crossed and dioecious species was significantly low (Loveless and Hamrick, 1984; Hamrick et al., 1992; Amos and Harwood, 1998). In addition, no statistically significant differentiation was found between male-female subpopulations, suggesting male-female subpopulations may share common ancestors and co-evolved. Dioecious plants have probably evolved from hermaphrodite (Barrett, 2002), the lower differentiation of male and female subpopulations might indicate that sex differentiation occurred earlier than genetic differentiation (Jia et al., 2015).

Bayesian analysis identified two putative clusters that were geographically structured and the subpopulation structure had little relationship with sex, which was consistent with previous research in H. rhamnoides (Chen et al., 2008). But for Myrica rubra, the male and female accessions can be divided into two sexual clusters although the genetic structure was low (Jia et al., 2015). Relatively high long-term migration rates (M) between two basins might reflect a historically more continuous species distribution (Bossart and Pashley, 1998). Moreover, high M values between pairs of male-female subpopulation (with $M$ values were $>0.8$ ) further explained no significant differentiation between them. As a fundamental microevolutionary force, gene flow underlines genetic differentiation among populations and influences the maintenance of genetic diversity within a species (Slatkin, 1994). Moreover, recent gene flow is of fundamental importance for analyzing the future genetic structure (Yao et al., 2007). In this study, little recent migration rates were detected between sexual subpopulations. This might be due to the inbreeding among kin restricting current seed/pollen dispersal of S. viminalis (Frankham et al., 2002), and the density effects of pollination services with a high density of adults can also promote short-distance pollen dispersal (inbreeding; Lowe et al., 2005; Yao et al., 2011).

In conclusion, although the genetic diversity of male and female subpopulations was high, there were no significant differences between them. Under less favorable environment in West Liao basin, the genetic diversity of male and female subpopulations was lower but still not significantly different. The subpopulations were geographically structured and had little relationship with sex. Moderate differentiation was detected among subpopulations of $S$. viminalis, but the differentiation between male-female subpopulations was not statistically significant, which was supported by high longterm migrate. However, recent migration between sexual subpopulations was low. Considering that the majority of genetic variance was within subpopulations in S. viminalis, so populations with higher genetic diversity and more number of private alleles should be gave priority to protection. During the process of ex situ conservation, artificial crossing or/and transplantation by cutting propagation should be carried out in order to increase the migration.

\section{AUTHOR CONTRIBUTIONS}

FZ and ZS designed the study. FZ, JM, JL, XP carried out the experiments. FZ, JM, LH, and ZS analyzed the data. FZ and JM wrote the manuscript and all authors approved the final version to be published.

\section{ACKNOWLEDGMENTS}

The authors sincerely thank Nan Jiang and Xiaoxuan Jia of Chinese Academy of Forestry for their help in drawing picture. Research in the laboratories has been supported by funding from the Fundamental Research Funds for the Central Non-profit Research Institution of CAF (Grant No. CAFYBB2016ZX01-3) and Special Fund for Forest Scientific Research in the Public Welfare of China (Grant No. 201304115).

\section{SUPPLEMENTARY MATERIAL}

The Supplementary Material for this article can be found online at: http://journal.frontiersin.org/article/10.3389/fpls.2016. 00330

Supplementary Figure 1 | Estimation of subpopulation structure based on Bayesian structuring by STRUCTURE vchsdatelsROCDateFalselsLunarDateFalseDay30Month12Year18992.3.4. (A) Mean log-likelihood value $( \pm S D)$ over each $K$-value. (B) Delta $K$-value for each $K$-value. (C) Histogram of structure analysis for the model with $K=2$.

Supplementary Table 1 | Genetic diversity and F-statistics of S. viminalis for 20 SSR loci.

Supplementary Table $2 \mid P$-values of five genetic parameters between male and female subpopulations by paired-sample $t$-test.

Supplementary Table $3 \mid \boldsymbol{P}$-values of five genetic parameters between male and female subpopulations for $\mathbf{2 0}$ loci by paired-sample $t$-test.

Supplementary Table $4 \mid \boldsymbol{P}$-values of five genetic parameters between two basins by one-way analysis of variance.

Supplementary Table 5 | Pairwise F $_{S T}$ values among ten male and female subpopulations. 
Supplementary Table 6 | Maximum-likelihood estimates and 95\% confidence intervals (in parentheses) of the long-term migration rate (M) and mutation-scaled effective population size ( $\theta$, square brackets) using the MIGRATE-N program are shown. Source localities are given in rows, recipient localities are in columns.

\section{REFERENCES}

Ainsworth, C. (2000). Boys and girls come out to play: the molecular biology of dioecious plants. Ann. Bot. 86, 211-221. doi: 10.1006/anbo. 2000.1201

Amos, W., and Harwood, J. (1998). Factors affecting levels of genetic diversity in natural populations. Phil. Trans. Soc. Lond. B. 353, 177-186. doi: 10.1098/rstb.1998.0200

Ashman, T. L., and Diefenderfer, C. (2001). Sex ratio represents a unique context for selection on attractive traits: Consequences for the evolution of sexual dimorphism. Am. Nat. 157, 334-347. doi: 10.1086/319192

Barker, J. H. A., Pahlich, A., Trybush, S., Edwards, K. J., and Karp, A. (2003). Microsatellite markers for diverse Salix species. Mol. Ecol. Notes. 3, 4-6. doi: 10.1046/j.1471-8286.2003.00332.x

Barrett, S. C. H. (2002). The evolution of plant sexual diversity. Nat. Rev. Genet. 3 , 274-284. doi: $10.1038 / \mathrm{nrg} 776$

Berlin, S., Trybush, S. O., Fogelqvist, J., Gyllenstrand, N., Hallingbaeck, H. R., Åhman, I., et al. (2014). Genetic diversity, population structure and phenotypic variation in European Salix viminalis L.(Salicaceae). Tree Genet. Genomes. 10, 1595-1610. doi: 10.1007/s11295-014-0782-5

Bossart, J. L., and Pashley, P. D. (1998). Genetic estimates of population structure and gene flow: limitations, lessons and new directions. Trends Ecol. Evol. 13, 202-206. doi: 10.1016/S0169-5347(97)01284-6

Buckley, N. E., and Avila-Sakar, G. (2013). Reproduction, growth, and defense trade-offs vary with gender and reproductive allocation in Ilex glabra (Aquifoliaceae). Am. J. Bot. 100, 357-364. doi: 10.3732/ajb. 1200603

Callahan, C. M., Rowe, C. A., Ryel, R. J., Shaw, J. D., Madritch, M. D., and Mock, K. E. (2013). Continental-scale assessment of genetic diversity and population structure in quaking aspen (Populus tremuloides). J. Biogeogr. 40, 1780-1791. doi: $10.1111 /$ jbi. 12115

Charpentier, M., Setchell, J. M., Prugnolle, F., Knapp, L. A., Wickings, E. J., Peignot, P., et al. (2005). Genetic diversity and reproductive success in mandrills (Mandrillus sphinx). Proc. Natl. Acad. Sci. U.S.A. 102, 16723-16728. doi: 10.1073/pnas.0507205102

Chen, G., Wang, Y., Zhao, C., Korpelainen, H., and Li, C. (2008). Genetic diversity of Hippophae rhamnoides populations at varying altitudes in the wolong natural reserve of China as revealed by ISSR markers. Silvae Genet. 57, 29-36.

Cornelissen, T., and Stiling, P. (2005). Sex-biased herbivory: a meta-analysis of the effects of gender on plant-herbivore interactions. Oikos 111, 488-500. doi: 10.1111/j.1600-0706.2005.14075.x

Dawson, T. E., and Bliss, L. C. (1989). Patterns of water use and the tissue water relations in the dioecious shrub, Salix arctica: the physiological basis for habitat partitioning between the sexes. Oecologia 79, 332-343. doi: 10.1007/bf003 84312

Dawson, T. E., and Ehleringer, J. R. (1993). Gender-specific physiology, carbon isotope discrimination, and habitat distribution in boxelder, Acer negundo. Ecology 74, 798-815. doi: 10.2307/1940807

Dostálek, T., Münzbergová, Z., and Plačková, I. (2014). High genetic diversity in isolated populations of Thesium ebracteatum at the edge of its distribution range. Conserv. Genet. 15, 75-86. doi: 10.1007/s10592-013-0522-7

Doyle, J. J. (1987). A rapid DNA isolation procedure for small quantities of fresh leaf tissue. Phytochem. Bull. 19, 11-15.

Dudley, L. S., and Galen, C. (2007). Stage-dependent patterns of drought tolerance and gas exchange vary between sexes in the alpine willow, Salix glauca. Oecologia 153, 1-9. doi: 10.1007/s00442-007-0712-4

Evanno, G., Regnaut, S., and Goudet, J. (2005). Detecting the number of clusters of individuals using the software STRUCTURE: a simulation study. Mol. Ecol. 14, 2611-2620. doi: 10.1111/j.1365-294X.2005.02553.x
Supplementary Table 7 | The mean migration rate and $\mathbf{( 9 5 \%}$ confidence interval) for a pair of subpopulations using by BAYESASS software are shown. Source localities are given in columns, recipient localities are in rows. The mean and $95 \%$ confidence interval for the non-migration rates are $0.833(0.675$, $0.992)$ and the migration rate mean and $95 \%$ confidence interval for data sets with 10 populations are $0.0185(3.12 \mathrm{E}-11,0.121)$

Falush, D., Stephens, M., and Pritchard, J. K. (2003). Inference of population structure using multilocus genotype data: linked loci and correlated allele frequencies. Genetics 164, 1567-1587.

Frankham, R., Briscoe, D. A., and Ballou, J. D. (2002). Introduction to Conservation Genetics. Cambridge: Cambridge University Press.

Hamrick, J. L., Godt, M. J. W., and Sherman-Broyles, S. L. (1992). Factors influencing levels of genetic diversity in woody plant species. New Forest. 6, 95-124. doi: 10.1007/BF00120641

Han, Y., Wang, L., Zhang, X., Korpelainen, H., and Li, C. (2013). Sexual differences in photosynthetic activity, ultrastructure and phytoremediation potential of Populus cathayana exposed to lead and drought. Tree Physiol. 33, 1043-1060. doi: 10.1093/treephys/tpt086

Heikkrujam, M., Kumar, J., and Agrawal, V. (2015). Genetic diversity analysis among male and female Jojoba genotypes employing gene targeted molecular markers, start codon targeted (SCOT) polymorphism and CAAT box-derived polymorphism (CBDP) markers. Meta Gene. 5, 90-97. doi: 10.1016/j.mgene.2015.06.001

Hermle, S., Vollenweider, P., Günthardt-Goerg, M. S., McQuattie, C. J., and Matyssek, R. (2007). Leaf responsiveness of Populus tremula and Salix viminalis to soil contaminated with heavy metals and acidic rainwater. Tree Physiol. 27, 1517-1531. doi: 10.1093/treephys/27.11.1517

Ilves, A., Lanno, K., Sammul, M., and Tali, K. (2013). Genetic variability, population size and reproduction potential in Ligularia sibirica (L.) populations in Estonia. Conserv. Genet. 14, 661-669. doi: 10.1007/s10592-013-0 459-x

Jia, H., Jiao, Y., Wang, G., Li, Y., Jia, H., Wu, H., et al. (2015). Genetic diversity of male and female Chinese bayberry (Myrica rubra) populations and identification of sex-associated markers. BMC Genomics.16:394. doi: 10.1186/s12864-015-1602-5

Jiang, D., Wu, G., Mao, K., and Feng, J. (2015). Structure of genetic diversity in marginal populations of black poplar (Populus nigra L.). Biochem. Syst. Ecol. 61, 297-302. doi: 10.1016/j.bse.2015.06.014

Johansson, M., Primmer, C. R., and Merilä, J. (2007). Does habitat fragmentation reduce fitness and adaptability? A case study of the common frog (Rana temporaria). Mol. Ecol. 16, 2693-2700. doi: 10.1111/j.1365-294x.2007.03 357.x

Karp, A., Hanley, S. J., Trybush, S. O., Macalpine, W., Pei, M., and Shield, I. (2011). Genetic improvement of willow for bioenergy and biofuelsfree access. J. Integr. Plant Biol. 53, 151-165. doi: 10.1111/j.1744-7909.2010.01015.x

Keller, S. R., Soolanayakanahally, R. Y., Guy, R. D., Silim, S. N., Olson, M. S., and Tiffin, P. (2011). Climate-driven local adaptation of ecophysiology and phenology in balsam poplar, Populus balsamifera L.(Salicaceae). Am. J. Bot. 98, 99-108. doi: 10.3732/ajb.1000317

Kikuchi, S., Suzuki, W., Ban, N., Kanazashi, A., and Yoshimaru, H. (2005). Characterization of eight polymorphic microsatellites in endangered willow Salix hukaoana. Mol. Ecol. Notes 5, 869-870. doi: 10.1111/j.1471-8286.2005.01098.x

Kim, M. S., Brunsfeld, S. J., McDonald, G. I., and Klopfenstein, N. B. (2003). Effect of white pine blister rust (Cronartium ribicola) and rust-resistance breeding on genetic variation in western white pine (Pinus monticola). Theor. Appl. Genet. 106, 1004-1010. doi: 10.1007/s00122-002-1141-8

Kim, M. S., Richardson, B. A., McDonald, G. I., and Klopfenstein, N. B. (2011). Genetic diversity and structure of western white pine (Pinus monticola) in North America: a baseline study for conservation, restoration, and addressing impacts of climate change. Tree Genet. Genomes. 7, 11-21. doi: 10.1007/s11295010-0311-0

Klang-Westin, E., and Perttu, K. (2002). Effects of nutrient supply and soil cadmium concentration on cadmium removal by willow. Biomass Bioenergy 23, 415-426. doi: 10.1016/S0961-9534(02)00068-5 
Lascoux, M., Thorsén, J., and Gullberg, U. (1996). Population structure of a riparian willow species, Salix viminalis L. Genet. Res. 68, 45-54. doi: 10.1017/S0016672300033875

Lee, K. M., Kim, Y. Y., and Hyun, J. O. (2011). Genetic variation in populations of Populus davidiana Dode based on microsatellite marker analysis. Genes Genom. 33, 163-171. doi: 10.1007/s13258-010-0148-9

Li, C., Xu, G., Zang, R., Korpelainen, H., and Berninger, F. (2007). Sex-related differences in leaf morphological and physiological responses in Hippophae rhamnoides along an altitudinal gradient. Tree Physiol. 27, 399-406. doi: 10.1093/treephys/27.3.399

Li, L., Zhang, Y., Luo, J., Korpelainen, H., and Li, C. (2013). Sex-specific responses of Populus yunnanensis exposed to elevated $\mathrm{CO}_{2}$ and salinity. Physiol. Plantarum. 147, 477-488. doi: 10.1111/j.1399-3054.2012.01676.x

Liu, J., Zheng, X., Potter, D., Hu, C., and Teng, Y. (2012). Genetic diversity and population structure of Pyrus calleryana (Rosaceae) in Zhejiang province, China. Biochem. Syst. Ecol. 45, 69-78. doi: 10.1016/j.bse.2012.06.027

Loveless, M. D., and Hamrick, J. L. (1984). Ecological determinants of genetic structure in plant populations. Annu. Rev. Ecol. Syst. 15, 65-95. doi: 10.1146/annurev.es.15.110184.000433

Lowe, A. J., Boshier, D., Ward, M., Bacles, C. F. E., and Navarro, C. (2005). Genetic resource impacts of habitat loss and degradation; reconciling empirical evidence and predicted theory for neotropical trees. Heredity 95, 255-273. doi: 10.1038/sj.hdy.6800725

Montesinos, D., Villar-Salvador, P., García-Fayos, P., and Verdú, M. (2012). Genders in Juniperus thurifera have different functional responses to variations in nutrient availability. New Phytol. 193, 705-712. doi: 10.1111/j.14698137.2011.03982.x

Nosrati, H., Husainpourfeizi, M. A., Khorasani, M., Razban-Haghighi, A., and Nikniazi, M. (2012). Sex ratio and genetic diversity in the dioecious Pistacia atlantica (Anacardiaceae). J. Agrobiol. 29, 41-46. doi: 10.2478/v10146-0120006-2

Peakall, R., and Smouse, P. E. (2012). GenAlEx 6.5: genetic analysis in Excel. Population genetic software for teaching and research-an update. Bioinformatics 28, 2537-2539. doi: 10.1093/bioinformatics/bts460

Perdereau, A. C., Kelleher, C. T., Douglas, G. C., and Hodkinson, T. R. (2014). High levels of gene flow and genetic diversity in Irish populations of Salix caprea L. inferred from chloroplast and nuclear SSR markers. BMC Plant Biol. 1:202. doi: 10.1186/s12870-014-0202-x

Pritchard, J. K., Stephens, M., and Donnelly, P. (2000). Inference of population structure using multilocus genotype data. Genetics 155, 945-959.

Przyborowski, J. A., and Sulima, P. (2010). The analysis of genetic diversity of Salix viminalis genotypes as a potential source of biomass by RAPD markers. Ind. Crop. Prod. 31, 395-400. doi: 10.1016/j.indcrop.2009.12.009

Reed, D. H., and Frankham, R. (2003). Correlation between fitness and genetic diversity. Conserv. Biol. 17, 230-237. doi: 10.1046/j.1523-1739.2003.01236.x

Renner, S. S., and Ricklefs, R. E. (1995). Dioecy and its correlates in the flowering plants. Am. J. Bot. 82, 596-606. doi: 10.2307/2445418

Shen, H., and Liu, D. (2001). Summary of genetic diversity. J. Biol. 18, 5-7.

Slatkin, M. (1994). "Gene flow and population structure," in Ecological Genetics, ed L. A. Real (Princeton, NJ: Princeton University Press), 3-17.

Stamati, K., Blackie, S., Brown, J. W. S., and Russell, J. (2003). A set of polymorphic SSR loci for subarctic willow (Salix lanata, S. lapponum and S. herbacea). Mol. Ecol. Notes 3, 280-282. doi: 10.1046/j.1471-8286.2003.00426.x

Stamati, K., Hollingsworth, P. M., and Russell, J. (2007). Patterns of clonal diversity in three species of sub-arctic willow (Salix lanata, Salix lapponum and Salix herbacea). Plant Syst. Evol. 269, 75-88. doi: 10.1007/s00606-0070578-2
Teixeira, H., Rodriguez-Echeverria, S., and Nabais, C. (2014). Genetic diversity and differentiation of Juniperus thurifera in Spain and Morocco as determined by SSR. PLoS ONE 9:e88996. doi: 10.1371/journal.pone.0088996

Trybush, S. O., Jahodová, Š., Čížková, L., Karp, A., and Hanley, S. J. (2012). High levels of genetic diversity in Salix viminalis of the Czech Republic as revealed by microsatellite markers. Bioenerg. Res. 5, 969-977. doi: 10.1007/s12155-0129212-4

Ucisik, A. S., and Trapp, S. (2006). Uptake, removal, accumulation, and phytotoxicity of phenol in willow trees (Salix viminalis). Environ. Toxicol. Chem. 25, 2455-2460. doi: 10.1897/05-457R.1

Wang, J., Li, Z., Guo, Q., Ren, G., and Wu, Y. (2011). Genetic variation within and between populations of a desert poplar (Populus euphratica) revealed by SSR markers. Ann. Forest Sci. 68, 1143-1149. doi: 10.1007/s13595-011-0119-6

Wang, Z., Kang, M., Liu, H., Gao, J., Zhang, Z., Li, Y., et al. (2014). High-level genetic diversity and complex population structure of Siberian apricot (Prunus sibirica L.) in China as revealed by nuclear SSR markers. PLOS ONE 9:e87381. doi: 10.1371/journal.pone.0087381

Wilson, G. A., and Rannala, B. (2003). Bayesian inference of recent migration rates using multilocus genotypes. Genetics 163, 1177-1191.

Xu, X., Yang, F. A. N., Xiao, X., Zhang, S., Korpelainen, H., and Li, C. (2008). Sexspecific responses of Populus cathayana to drought and elevated temperatures. Plant Cell Environ. 31, 850-860. doi: 10.1111/j.1365-3040.2008.01799.x

Yao, X., Ye, Q., Kang, M., and Huang, H. (2007). Microsatellite analysis reveals interpopulation differentiation and gene flow in the endangered tree Changiostyrax dolichocarpa (Styracaceae) with fragmented distribution in central China. New Phytol. 176, 472-480. doi: 10.1111/j.1469-8137.2007.02175.x

Yao, X., Zhang, J., Ye, Q., and Huang, H. (2011). Fine-scale spatial genetic structure and gene flow in a small, fragmented population of Sinojackia rehderiana (Styracaceae), an endangered tree species endemic to China. Plant Biol. 13, 401-410. doi: 10.1111/j.1438-8677.2010.00361.x

Yeh, F. C., Yang, R. C., Boyle, T. B., Ye, Z. H., and Mao, J. X. (1997). POPGENE, the User-Friendly Shareware for Population Genetic Analysis. Edmonton, AB: Molecular Biology and Biotechnology Center, University of Alberta.

Young, A., Boyle, T., and Brown, T. (1996). The population genetic consequences of habitat fragmentation for plants. Trends Ecol. Evol. 11, 413-418. doi: 10.1016/0169-5347(96)10045-8

Zhai, F. F., and Sun, Z. Y. (2015). Progress in study on sexual differences of woody dioecious plants. Sci. Silvae Sin. 51, 110-116. doi: 10.11707/j.10017488.20151014

Zhao, H., Xu, X., Zhang, Y., Korpelainen, H., and Li, C. (2011). Nitrogen deposition limits photosynthetic response to elevated $\mathrm{CO}_{2}$ differentially in a dioecious species. Oecologia 165, 41-54. doi: 10.1007/s00442-010-1763-5

Zong, J., Zhao, T., Ma, Q., Liang, L., and Wang, G. (2015). Assessment of genetic diversity and population genetic structure of Corylus mandshurica in China using SSR markers. PLoS ONE 10:e0137528. doi: 10.1371/journal.pone.0137528

Conflict of Interest Statement: The authors declare that the research was conducted in the absence of any commercial or financial relationships that could be construed as a potential conflict of interest.

Copyright (C) 2016 Zhai, Mao, Liu, Peng, Han and Sun. This is an open-access article distributed under the terms of the Creative Commons Attribution License (CC BY). The use, distribution or reproduction in other forums is permitted, provided the original author(s) or licensor are credited and that the original publication in this journal is cited, in accordance with accepted academic practice. No use, distribution or reproduction is permitted which does not comply with these terms. 